\title{
Giardia duodenalis in Alpine (Rupicapra rupicapra rupicapra) and Apennine (Rupicapra pyrenaica ornata) chamois
}

\author{
Claudio De Liberato ${ }^{1}$, Federica Berrilli², Marianna Marangi ${ }^{3}$, Maristella Santoro², Tiziana Trogu ${ }^{4}$, Lorenza Putignani ${ }^{5}$, \\ Paolo Lanfranchi ${ }^{4}$, Francesco Ferretti ${ }^{6}$, Stefano D'Amelio $^{7}$ and Annunziata Giangaspero ${ }^{3^{*}}$
}

\begin{abstract}
Background: Although chamois Rupicapra spp. are the most abundant mountain ungulates in Europe, no data are available on the presence of Giardia duodenalis infecting these species.

Methods: A total of 157 fecal samples from Alpine Rupicapra rupicapra rupicapra and Apennine Rupicapra pyrenaica ornata chamois were tested for the presence of $G$. duodenalis by immunofluorescence test, quantitative Real Time PCR and end-point PCR for genotype characterization.

Results: G. duodenalis was detected in R. r. rupicapra and R. p. ornata, with a percentage value of 4.45 (5.82 and $1.85 \%$, respectively), and a cyst burden of up to 31,800 cysts/g of feces. Assemblages A/Al and E were identified in R. r. rupicapra and assemblage A/Alll in R. p. ornata.

Conclusions: The present study represents the first record of Giardia duodenalis in Rupicapra spp., suggesting that these wild bovids can play an epidemiological role in environmental contamination and transmission of both zoonotic and non-zoonotic genotypes.
\end{abstract}

Keywords: Giardia duodenalis, Rupicapra rupicapra rupicapra, Rupicapra pyrenaica ornata, IF, aPCR, end-point-PCR

\section{Background}

The flagellate Giardia duodenalis is one of the most common intestinal parasites in humans and several animal species worldwide $[1,2]$. At present, eight assemblages have been genetically recognized $(\mathrm{A}-\mathrm{H})$, which differ in host specificity: zoonotic assemblages $\mathrm{A}$ and $\mathrm{B}$ infect humans and a wide variety of domestic and wild mammals; assemblages $\mathrm{C}$ and $\mathrm{D}$ are typically isolated from dogs; assemblage $\mathrm{E}$ is associated with hoofed livestock; assemblage $\mathrm{F}$ infects cats; assemblage $\mathrm{G}$ infects rats [3], and assemblage $\mathrm{H}$ infects marine mammals (pinnipeds) [4]. It is now believed that at least some of these assemblages should be considered "true species" $[5,6]$.

Given this great genetic heterogeneity, it is hard to determine the role of animals as a source for human infection, and viceversa [7]; this is possible only by

\footnotetext{
* Correspondence: annunziata.giangaspero@unifg.it

${ }^{3}$ Dipartimento di Scienze Agrarie, degli Alimenti e dell'Ambiente, Università degli Studi di Foggia, 71121 Foggia, Italy

Full list of author information is available at the end of the article
}

performing detailed genetic analysis $[8,9]$, even as far as the sub-assemblage level. While the role of domestic animals (pets and livestock) in G. duodenalis epidemiology has been thoroughly studied, wild animals have only recently been considered as having a potential role. In addition to being a possible source of infection for humans, wild animals can be endangered by the spillover of parasites from domestic animals and even people [10], especially in the case of small populations which are important for wildlife conservation [11].

G. duodenalis has been recorded in wild ungulates wordwide $[8,9,12-15]$. Most of these records refer to cervids, in which the presence of zoonotic and non-zoonotic genotypes have been documented (reviewed by [6]).

The chamois (Artiodactyla: Bovidae) is the most abundant mountain ungulate in Europe and the Near East. Two species are recognised in the genus Rupicapra: the Northern chamois, Rupicapra rupicapra, with seven subspecies, including the Alpine chamois $R$. r. rupicapra, and the Southern chamois, Rupicapra pyrenaica, with 
three subspecies, including the Apennine chamois $R . p$. ornata $[16,17]$.

Despite the geographical abundance of Rupicapra species in Europe, no data are available on the presence of G. duodenalis infecting chamois. This study aimed to determine the presence of G. duodenalis, and to quantify and characterize isolates from two subspecies of chamois: $R$. r. rupicapra living in northern Italy (Alps) and $R$. p. ornata, living in central Italy (Apennines).

\section{Methods}

\section{Study areas, animals and collection of fecal samples}

The study took place in three areas of Italy. The first is in the Lecchesi Alps and Pre-Alps, a hunting territory in Lombardy region, with an area of $253 \mathrm{~km}^{2}\left(45^{\circ} 59^{\prime} \mathrm{N}\right.$, $9^{\circ}$ 32 'E), ranging from 300 to $>2000 \mathrm{~m}$ a.s.l. Here the $R$. $r$. rupicapra population in 2014 was estimated as 2077 individuals, giving an average population density of 8.2 chamois $/ \mathrm{km}^{2}$ (Province of Lecco, unpublished data). The second area is in the Lepontine Alps, in the hunting district of Piedmont region (VCO2Ossola Nord), with an extent of 72,740 ha $\left(46^{\circ} 07^{\circ} \mathrm{N}\right.$, $8^{\circ} 17^{\prime} \mathrm{E}$ ), ranging from 700 to $2400 \mathrm{~m}$ a.s.l. Here the chamois population was estimated as 1328 individuals in 2014 , with an average density of 6.7 subjects $/ \mathrm{km}^{2}$ [18]. The third area is in central Italy, in the Abruzzo, Lazio and Molise National Park (ALMNP, $497 \mathrm{~km}^{2}, 41^{\circ} 44^{\prime} \mathrm{N}, 13^{\circ} 54^{\prime} \mathrm{E}$ ), where samples were collected in Val di Rose, Mt. Meta, and Mt. Amaro subareas, ranging from 1650 to $2242 \mathrm{~m}$ a.s.l. In ALMNP, about 600 individuals of $R$. p.ornata were counted in 2014 [19], with local population densities of up to over 20 individuals $/ \mathrm{km}^{2}$ [20, 21].

Between August 2013 and January 2014, 103 fresh fecal samples were collected from $R$. r. rupicapra chamois harvested during the hunting season, whereas the 54 fecal samples from $R$. p. ornata were collected from the ground soon after defecation. To avoid the risk of collecting feces from the same individuals, sampling was carried out on different slope sites and took into account, as far as possible, the animals' sex and age. Fresh fecal specimens were collected and put into plastic bags, which were labeled and immediately packed in an insulated container with ice or cold packs. Specimens were then transported to the laboratory and processed within 1-3 days after collection.

\section{Giardia detection}

All 157 faecal samples were examined using an immunofluorescence (IF) test for the detection of G. duodenalis (Kit Merifluor ${ }^{\circ}$ Meridian Diagnostic, Cincinnati, OH, USA).

The positive samples were frozen and subjected to Real-Time PCR for quantitative analysis ( $q$ PCR) using the SSU-rDNA gene, and to end-point PCR for genotyping using two genes i.e. SSU-rDNA and $g d h$.

\section{DNA extraction}

I.F. positive fecal samples were washed three times with PBS and subjected to 5 cycles of freezing with dry ice and thawing at $95{ }^{\circ} \mathrm{C}$ (5 min each step). DNA extraction was automatically performed by EZ1 BioRobot (Qiagen, Germany) following the manufacturer's instructions. To obtain a high quality DNA, samples were purified by Amicon Ultra-0.5 Centrifugal Filter Unit (Millipore) following the manufacturer's instructions.

\section{Quantitative ( $q \mathrm{PCR}$ ) and melting curve analysis}

A sequence of $G$. duodenalis SSU-rDNA gene (KJ888984) [22] was selected as reference target to design the plasmid control. The pEX-A vector (Eurofins, MWG/Operon, Ebersberg, Germany) was used to insert a fragment of approximately 293 bp of G. duodenalis SSU-rDNA gene.

The concentration of the pEX-A2 G. duodenalis plasmid was measured using a fluorometer, and the corresponding copy number was calculated using the following equation:

pEX-A2 G. duodenalis (copy numbers) $=6.02 \times 10^{23}$ $(\mathrm{copy} / \mathrm{mol}) \times \mathrm{pEX}-\mathrm{A} 2 \mathrm{G}$. duodenalis amount $\left(0.31 \times 10^{-5}\right.$ $\mathrm{g} / \mathrm{ml}) / \mathrm{pEX}-\mathrm{A} 2 \mathrm{G}$. duodenalis length $(293 \mathrm{bp}+2450 \mathrm{bp}) \times$ 660 (g/mol/bp) [23].

Ten-fold serial dilutions of the pEX-A2 G. duodenalis plasmid (from $1.03 \times 10^{7}$ to $1.03 \times 10^{-3}$ copies/ $\mu \mathrm{l}$ ) were used to assess the sensitivity, repeatability and reproducibility parameters of the assay, and to determine the quantity of the unknown samples based on linear regression calculations of the standard curve.

Amplifications and melting analysis were performed in the CFX-96 Real Time Instrument (BioRad, Italy). G. duodenalis ssRNA primers were GiarF (5'- GAC GCT CTC CCC AAG GAC-3') and GiarR (5'- CTG CGT CAC GCT GCT CG-3') [24].

The PCR mixture (final volume $20 \mu \mathrm{l}$ ) contained $1 \mu \mathrm{l}$ of the plasmid-based control (or $5 \mu$ of genomic DNA sample from 1 to $5 \mathrm{ng}$ ), 5X EvaGreen ${ }^{\circ}$ Reagent (cat. No. 172-5201; BioRad, Italy) and $0.5 \mu \mathrm{M}$ final concentration of each forward and reverse primer. Samples without genomic DNA (negative controls) were included in each PCR run. The cycling conditions in a CFX-96 thermocycler (BioRad) were as follows: initial denaturation at $98^{\circ}$ $\mathrm{C}$ for $2 \mathrm{~min}$, followed by amplification for 35 cycles of $98{ }^{\circ} \mathrm{C}$ for $5 \mathrm{~s}$ and $55.6^{\circ} \mathrm{C}$ for $15 \mathrm{~s}$.

Fluorescence data were collected at the end of each cycle as a single acquisition. After amplification, the PCR products were melted by raising the temperature from 70 to $95{ }^{\circ} \mathrm{C}$, with an increment of $0.5{ }^{\circ} \mathrm{C} / 5 \mathrm{~s}$, in order to denature and re-anneal before the high resolution melting; changes in fluorescence were recorded 
with changes in temperature $(\mathrm{d} F / \mathrm{d} T)$ and plotted against changes in temperature. The resolution melting curve (MC) profile was then analyzed using Precision Melt Analysis $^{\mathrm{Th}}$ software version 1.2, with fluorescence (MC) normalization by selecting the linear region before and after the melting transition. The melting temperature (Tm) was interpolated from the normalized data as the temperature at 50 \% fluorescence. Samples' melting curves were distinguished by plotting the fluorescence difference between normalized melting curves. Tm and standard deviation $(S D)$ were recorded for each positive control.

Test-positive samples were identified on the basis of a single melting peak, which was consistent with that of the homologous plasmid control. The melting peak was $92.50{ }^{\circ} \mathrm{C}$ for G. duodenalis SSU-rDNA.

The copy number for each positive sample was calculated by relating the $C t$ mean value of each sample obtained in $q$ PCR to a standard curve obtained from the respective plasmid control. Since the number of copies of the SSU-rDNA gene ranges from 60 to 130 in one Giardia nucleus [25], we considered an average of 95 copies in one nucleus and a total for 4 nuclei of 380 copies in one cyst. The number of cysts in each sample was calculated as the number of copies obtained in $q$ PCR divided by 380 in $1 \mu \mathrm{l}$ and then in $100 \mu \mathrm{l}$ (since the volume of DNA after extraction is $100 \mu \mathrm{l}$ ). Finally, since the number of cysts in each sample was obtained in $200 \mathrm{mg}$ of fecal sample, the results were transformed for cysts per gram (CPG) with the formula: number of cysts obtained in $200 \mathrm{mg}$ of fecal sample X 5 .

\section{End-point PCR}

A nested PCR was performed to amplify a 130 bp region from the SSU-rDNA gene, using the primers RH4 and RH11 for the first step, and the primers GiarR and GiarF in the second amplification round, as used for $q \mathrm{PCR}$ [24]. An additional analysis was carried out by using a semi-nested PCR to amplify a $432 \mathrm{bp}$ fragment with the primers GDHeF and GDHiR in the primary reaction, and GDHiF and GDHiR in the secondary [26]. In all PCR reactions, positive (Giardia DNA) and negative (no template added) controls were added. All PCRs were carried out in a $25 \mu \mathrm{L}$ volume containing $12.5 \mu \mathrm{L}$ PCR master mix 2X (Promega), $5 \mu \mathrm{L}$ template DNA, $0.6 \mathrm{mM}$ of each primer and $0.1 \mathrm{mM} \mathrm{BSA}, 4 \%$ dimethyl sulfoxide (DMSO), and were performed in a TProfessional Basic Thermocycler (Biometra GmbH, Göttingen, Germany). PCR products were visualized by electrophoresis on $1 \%$ agarose gel stained by SYBR Safe DNA gel stain (Invitrogen). Amplicons were purified using the mi-PCR Purification Kit (Metabion $\mathrm{GmbH}$ ). Both strands were sequenced by Bio-Fab Research s.r.l. (Rome, Italy). Sequences were edited with FinchTV 1.4 software (Geospiza, Inc, Seattle, WA, USA). To assign Giardia isolates to the correct assemblage, a comparison of the $S S U-r D N A$ sequences by multiple alignments was performed using ClustalW2 software against known sequences available in GenBank. To test the significance of the results and to identify the subassemblage, a phylogenetic analysis was performed using MEGA6 software to compare the SSU-rDNA and $g d h$ sequences with those of reference strains from different hosts. The best-fit model and parameters for tree construction were selected using the jModeltest software by the Akaike Information Criterion (AIC).

\section{Results}

G. duodenalis was detected by microscopy in seven out of the 157 fecal samples examined, (4.45\%; $\mathrm{CI}=1.8-9.1)$. In R. r. rupicapra and R. p. ornata, a percentage of $5.82 \%$ $(6 / 103)(\mathrm{CI}=2.2-12.5)$ and $1.85 \%(1 / 54) \quad(\mathrm{CI}=0.5-9.8)$ were registered, respectively. All samples which tested positive to microscopy were also positive to $q \mathrm{PCR}$ and end-point PCR to one or both genes (i.e. SSU-rDNA, $g d h$ ). Overall, two assemblages i.e. A (with sub-assemblages AI and AIII) and E were identified (Table 1), and combined analysis of the two loci revealed no discrepancies in assemblage assignment.

At the SSU-rDNA locus, G. duodenalis assemblage A sequences (chamois no.s 10, 55, and 71) were identical to those from different hosts, including white-tailed deer in the USA (Genbank accession number KJ867494) previously reported by [27], dairy cattle (KF843922) in China [28] and Dutch patients (AY826206) [29] (Fig. 1). The isolates from chamois no.s 26, 32 and 93 matched with several assemblage $\mathrm{E}$ isolates from livestock (100\% similarity). These assignments were confirmed by the phylogenetic analysis as evidenced in Fig. 1.

Phylogenetic analysis of $g d h$ sequences showed that isolate no. 71 from $R$. r. rupicapra clustered within subassemblage A/AI, sharing the same sequences as those from a large number of isolates from humans (L40509) [29, 30], several domestic animals, including cattle (EF507642) [31], and also from water (KM190761) [32], whereas isolate no. 10 from $R$. p.ornata clustered within the sub-assemblage AIII, together with a Giardia isolate from roe deer in the Netherlands (DQ100288) [29] and red deer in Poland (HM150751) [9] (Table 1; Fig. 2). Bootstrap analysis indicated strong statistical support for these grouping. PCR based on gdh locus failed for the other Giardia isolates. The nucleotide sequences obtained in this study have been deposited in EMBL/GenBank database under accession number from LN875379 to LN875384 for the SSU-rDNA gene and KT270858-KT270859 for the $g d h$ gene.

The number of Giardia cysts in test-positive samples were predicted to range from 263 to 31,800 per gram of feces (Table 1). 
Table 1 Number of individual chamois (Rupicapra r. rupicapra and Rupicapra p. ornata) investigated and test-positive to Giardia duodenalis by microscopy, QPCR and end-point PCR analysis

\begin{tabular}{|c|c|c|c|c|c|c|c|}
\hline \multirow{2}{*}{$\begin{array}{l}\text { Collection } \\
\text { sites }\end{array}$} & \multirow[t]{2}{*}{ Species } & \multirow{2}{*}{$\begin{array}{l}\text { Animal } \\
\text { number }\end{array}$} & \multicolumn{3}{|c|}{ Giardia duodenalis } & \multirow{2}{*}{$\begin{array}{l}\text { Assemblage/ } \\
\text { Sub- } \\
\text { assemblage }\end{array}$} & \multirow{2}{*}{$\begin{array}{l}\text { No. of } \\
\text { CPG }\end{array}$} \\
\hline & & & Microscopy & $q \mathrm{PCR}$ & $P C R$ & & \\
\hline \multirow[t]{13}{*}{ ALPS } & \multirow[t]{13}{*}{ Rupicapra r. rupicapra } & $1-3$ & - & - & - & - & - \\
\hline & & 4 & + & + & + & A & 382 \\
\hline & & $5-25$ & - & - & - & - & - \\
\hline & & 26 & + & + & + & E & 326 \\
\hline & & $27-31$ & - & - & - & - & - \\
\hline & & 32 & + & + & + & E & 587 \\
\hline & & $33-54$ & - & - & - & - & - \\
\hline & & 55 & + & + & + & A & 263 \\
\hline & & $56-70$ & - & - & - & - & - \\
\hline & & 71 & + & + & + & $\mathrm{A} / \mathrm{Al}$ & 31,800 \\
\hline & & $72-92$ & - & - & - & - & - \\
\hline & & 93 & + & + & + & $E$ & 11,200 \\
\hline & & $94-103$ & - & - & - & - & - \\
\hline \multirow[t]{3}{*}{ APENNINES } & \multirow[t]{3}{*}{ Rupicapra p. ornata } & $1-9$ & - & - & - & - & - \\
\hline & & 10 & + & + & + & A/AllI & 618 \\
\hline & & $10-54$ & - & - & - & - & - \\
\hline
\end{tabular}

CPG cysts per gram of faeces calculated by $q P C R$

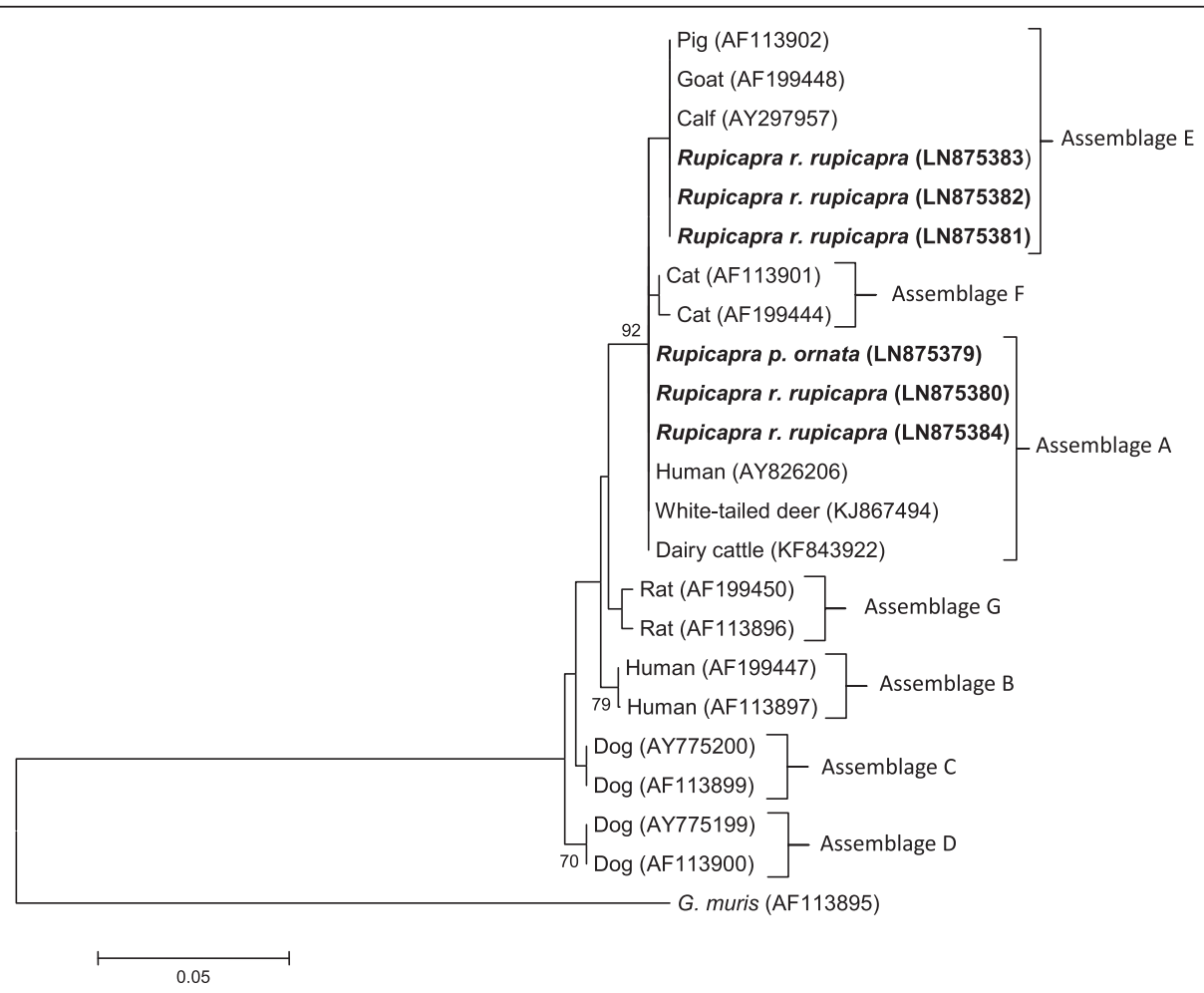

Fig. 1 Neighbor-Joining tree of the SSU-rDNA Giardia sequences. Six sequences from the present study (in bold) and 16 reference sequences representing assemblages A-G were included in the analysis for comparative purposes. Accession numbers of publicly available reference sequences are indicated. The evolutionary distances were computed using the Tamura 3-parameter method and a bootstrap test based on 1000 replicates. Bootstrap values at nodes $<70$ are not indicated. Giardia muris (AF113895) represents the outgroup 


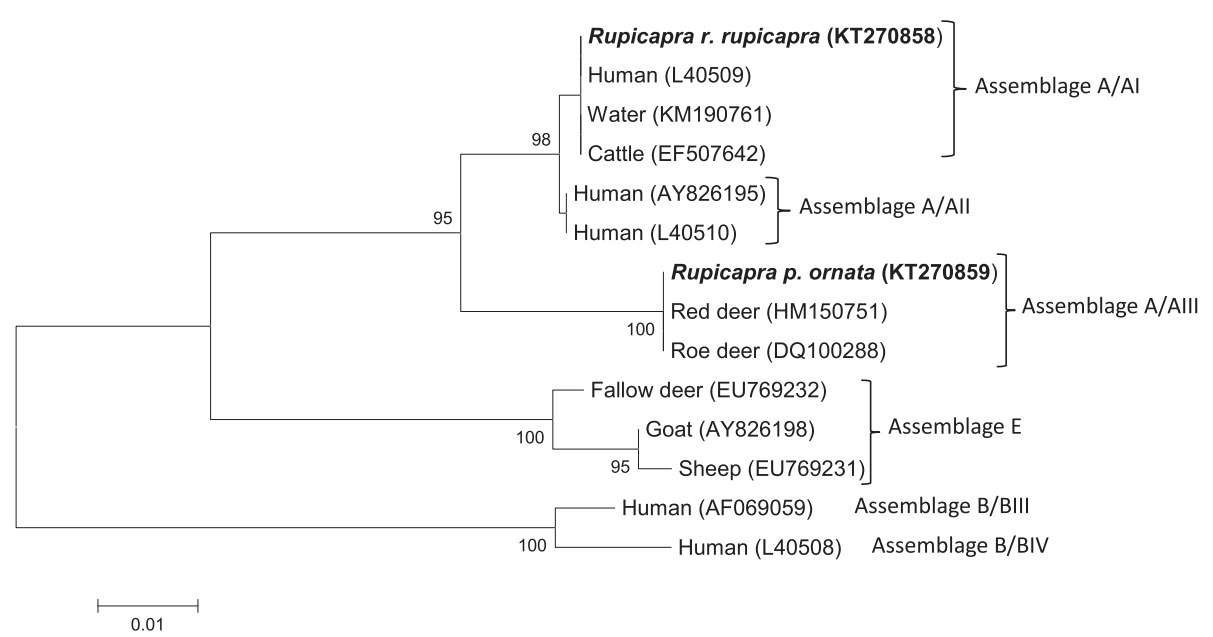

Fig. 2 Neighbor-Joining tree of the gdh Giardia sequences. Two sequences from the present study (in bold) and 12 reference sequences representing assemblage/sub-assemblages $\mathrm{A} / \mathrm{Al}, \mathrm{A} / \mathrm{All}, \mathrm{A} / \mathrm{AllI}, \mathrm{B} / \mathrm{BIII}, \mathrm{B} / \mathrm{BIV}$ and assemblage $\mathrm{E}$ were included in the analysis for comparative purposes. Accession numbers of publicly available reference sequences are indicated. The evolutionary distances were computed using the Tamura 3-parameter method and a bootstrap test based on 1000 replicates. Bootstrap values at nodes $<70$ are not indicated

\section{Ethics}

This research did not involve purposeful killing of animals. All fecal samples were gathered from dead free-ranging chamois legally shot by hunters in accordance with the Italian Law (157 of 11/02/1992) which implies that hunters have to carry culled wild ungulates to the control centres where, for each subject, age, sex, the shooting area and morpho-biometric measures are registered. Thus, no animals were killed specifically for this study.

\section{Discussion}

This is the first report of G. duodenalis in Rupicapra spp. Noticeably, the protist was found both in $R$. r. rupicapra and $R$. p. ornata, two different chamois subspecies living in quite distinct geographical areas, with an overall percentage value of $4.45 \%$ (5.82 and $1.85 \%$, respectively), and a cyst burden of up to 31,800 cysts/g of feces. Assemblages A (AI and AIII) and E were detected.

Regarding the G. duodenalis genetic groups, it is known that assemblage A recognizes four sub-assemblages (AI, AII, AIII and AIV) [3]. Sub-assemblages AI and AII are found in both humans and animals; sub-assemblage AI the zoonotic subtype - is preferentially found in livestock and pets, but has also been found in wild hoofed animals worldwide [6]; in Europe it has mostly been detected in cervids, i.e. fallow deer (Dama dama) in Italy [8], and red deer (Cervus elaphus) and roe deer (Capreolus capreolus) in Croatia [15]. Sub-assemblage AII is predominantly found in humans, whereas sub-assemblage AIII appears to be specifically associated with wild ungulates [6]; it has been isolated from cervids, i.e. red deer and roe deer in Croatia [15] and Poland [9], but also from cats [5, 33], and in a few cases from cattle [7]. AIV is almost exclusively found in domestic ungulates, and similarly to AIII it is only animal-related; therefore, both sub-assemblages are considered non-zoonotic [6].

Assemblage $\mathrm{E}$ is relatively host-specific, or rather 'group-specific', since it is limited to 'hoofed livestock' i.e. cattle, sheep, goats and pigs [6, 34-36], and for this reason it is known as the 'livestock genotype' [6]. However, assemblage $\mathrm{E}$ has been also detected in a wild hoofed cervid, i.e. fallow deer [33].

In the present study, the detection of assemblages $\mathrm{A}$ and $E$ in chamois living in the Italian Alps and Apennines was not unexpected. It shows that also $R . r$. rupicapra and $R$. p. ornata chamois harbor assemblages/sub-assemblages $\mathrm{A} / \mathrm{AI} / \mathrm{AIII}$, and confirms that assemblage $\mathrm{E}$ is associated to wild hoofed mammals, not only cervids [33] but also wild bovids, such as chamois Rupicapra $r$. rupicapra. In view of this, the term 'livestock genotype' commonly used to classify genetic group E may be considered outdated and could possibly be replaced with the term 'hoofed animal genotype'.

The presence of both assemblages A/AI and E in Alpine chamois can be related to their sharing of pastures with cattle and/or sheep and/or goats, as well as with cervids. In summer, farmers move their livestock up to high altitude alpine pastures, thus facilitating interaction with wild mountain ungulates [37]. Moreover, in addition to chamois, other species of wild ungulates are present in the alpine areas investigated; therefore, it is not only red deer and roe deer - cervid species found harbouring subassemblage AI Giardia in Croatia [15]- which may have an epidemiological role for Giardia trasmission, but also 
alpine ibex (Capra ibex), a bovid species as yet uninvestigated for the presence of Giardia.

Furthermore, unlike other Alpine areas (i.e. the Dolomites), which attract thousands of human visitors involved in trekking and mountaineering, and where "tourist-borne" arrival of Giardia may be considered possible [14], the possibility of human-borne contamination by sub-assemblage AI appears unlikely in the $R$. r. rupicapra sampling areas, due to the remoteness of this territory accessible only to a few shepherds in summer and hunters in autumn. This seems to confirm that domestic and wild animals play a greater role in the dissemination of sub-assemblage AI than humans [6].

Conversely, in the Apennine area investigated where one positive chamois was detected (Val di Rose), the $R$. $p$. ornata population is totally isolated from domestic ruminants and never shares pastures with them [38]; more importantly, red deer and roe deer are present. Both species were reintroduced to ALMNP in 1972-1987 [39]; however, while red deer are present at high densities in the chamois range (with peaks of $0.5-1$ deer/ha, in the grasslands of Val di Rose and Mt. Amaro), roe deer density is very limited, at least in summer [21,38]. Based on this, and coupled with AIII detection in red deer and roe deer in Croatia [15] and in Poland [9], detection of wild ungulate-related sub-assemblage AIII [6] in the Apennine chamois can be fully justified.

Finally, although none of the investigated positive subjects showed signs of diarrhea, since only formed feces were collected, and the Giardia cyst burden was up to 31,800 cysts/g of feces, the pathogenic role of Giardia in wildlife remains unclear.

\section{Conclusions}

The findings of the present study indicate that Rupicapra spp. chamois harbor G. duodenalis. This is the first report of assemblage $\mathrm{A} / \mathrm{AI}$ and assemblage $\mathrm{E}$ in $R, r$ r rupicapra and AIII in R. p. ornata. The epidemiological roles that these wild bovids play in environmental contamination (including watercourses and watersheds) and transmission to other wild and domestic mammals or even humans, of zoonotic (A/AI) and/or non-zoonotic assemblages/sub-assemblages (E, AIII), require further investigation, as does the impact of Giardia on the health and sustainability of chamois populations, together with the possible cumulative effects of other pathogens [11].

\section{Abbreviations}

ALMNP: Abruzzo, Lazio and Molise National Park; qPCR: Quantitative real time PCR.

\section{Competing interests}

The authors declare that they have no conflict of interests.

\section{Authors' contributions}

SDA, AG and PL conceived the study. CDL performed the microscopy study. FB, MM, MS and LP carried out the molecular genetic studies. TT and FF collected samples. AG, CDL and FB drafted the paper, and all authors contributed significantly to editing the manuscript. All authors read and approved the final version of the manuscript.

\section{Acknowledgments}

The authors wish to thank Professor Sandro Lovari for his helpful advice and discussion on chamois ecology.

The authors are also grateful to the Members and Management Committee of the Alpine hunting districts (Alpi Lecchesi, Prealpi Lecchesi and VCO2Ossola Nord and the Abruzzo, Lazio and Molise National Park Agency) for their logistical support and to the Province of Lecco (Settore Ambiente, Ecologia, Caccia e Pesca) for chamois census data. We also thank Nicoletta Formenti, Marta Bonfanti, Selene Partesana, Silvia Riontino and Stefano Sartorio, Davide Scornavacca and several students for their precious help in the field activities.

The study was funded by MIUR-Relevant Italian Project (PRIN) grant number: 2010P7LFW4 (2013-2016) - 'Genomics and host-pathogen interactions in chamois;; it has also been supported by Italian Ministry of Health (Ricerca Corrente nos. RC201302P002991 and RC201302G003050- 2013, and RC201402G003251 - 2014) from Ospedale Pediatrico Bambino Gesù, Roma.

\section{Author details}

'Istituto Zooprofilattico Sperimentale del Lazio e della Toscana "M. Aleandri", 00178 Roma, Italy. ${ }^{2}$ Dipartimento di Medicina sperimentale e Chirurgia, Università degli Studi di Roma 'Tor Vergata', 00133 Roma, Italy. 'Dipartimento di Scienze Agrarie, degli Alimenti e dell'Ambiente, Università degli Studi di Foggia, 71121 Foggia, Italy. ${ }^{4}$ Dipartimento di Scienze veterinarie e di Sanità pubblica, Università degli Studi di Milano, 20133 Milano, Italy. ${ }^{5}$ Unità di Parassitologia e Unità di Ricerca di Metagenomica, Bambino Gesù, Ospedale Pediatrico e Istituto di Ricerca, 00165 Roma, Italy. ${ }^{6}$ Dipartimento di Scienze della Vita, Università di Siena, 53100 Siena, Italy. ${ }^{7}$ Dipartimento di Sanità pubblica e Malattie infettive, Università degli Studi di Roma 'Sapienza', 00185 Roma, Italy.

Received: 9 August 2015 Accepted: 3 December 2015

Published online: 21 December 2015

\section{References}

1. Thompson RCA. The zoonotic significance and molecular epidemiology of Giardia and giardiasis. Vet Parasitol. 2004;126:15-35.

2. Yang R, Reid A, Lymbery A, Ryan U. Identification of zoonotic Giardia genotypes in fish. Int J Parasitol. 2010;40:779-85.

3. Monis PT, Andrews RH, Mayrhofer G, Ey PL. Genetic diversity within the morphological species Giardia intestinalis and its relationship to host origin. Infect Genet Evol. 2003;3:29-38.

4. Lasek-Nesselquist E, Welch DM, Sogin M. The identification of a new Giardia duodenalis assemblage in marine vertebrates and a preliminary analysis of G. duodenalis population biology in marine systems. Int J Parasitol. 2010;40: 1063-74.

5. Monis PT, Caccio SM, Thompson RCA. Variation in Giardia: towards ataxonomic revision of the genus. Trends Parasitol. 2009;25:93-100.

6. Ryan U, Cacciò SM. Zoonotic potential of Giardia. Int J Parasitol. 2013;43: 943-56.

7. Sprong H, Cacciò SM, van der Giessen JWB. Identification of zoonotic genotypes of Giardia duodenalis. PLoS Negl Trop Dis. 2009; doi:10.1371/ journal.pntd.0000558.

8. Lalle M, di Regalbono AF, Poppi L, Nobili G, Tonanzi D, Pozio E, et al. A novel Giardia duodenalis assemblage A subtype in fallow deer. J Parasitol. 2007;93:426-8.

9. Solarczyk P, Majewska AC, Moskwa B, Cabaj W, Dabert M, Nowosad P. Multilocus genotyping of Giardia duodenalis isolates from red deer (Cervus elaphus) and roe deer (Capreolus capreolus) from Poland. Folia Parasitol. 2012;59:237-40.

10. Daszak $P$, Cunningham AA, Hyatt AD. Emerging infectious diseases of wildlife - threats to biodiversity and human health. Science. 2000;287:443-9.

11. Appelbee AJ, Thompson RCA, Olson ME. Giardia and Cryptosporidium in mammalian wildlife - current status and future needs. Trends Parasitol. 2005:8:370-6. 
12. Trout JM, Santin M, Fayer R. Identification of assemblage A Giardia in white-tailed-deer. J Parasitol. 2003:89:1254-5.

13. Robertson L, Forberg T, Hermansen L, Hamnes IS, Gjerde B. Giardia duodenalis cysts isolated from wild moose and reindeer in Norway: genetic characterization by PCR-RFLP and sequence analysis at two genes. J Wildl Dis. 2007:43:576-85.

14. Kutz SJ, Thompson RCA, Polley L, Kondola K, Nagy J, Wielinga CM, et al. Giardia assemblage A: human genotype in muskoxen in the Canadian Arctic. Parasit Vectors. 2008;1:32.

15. Beck R, Sprong H, Lucinger S, Pozio E, Cacciò SM. A large survey of Croatian wild mammals for Giardia duodenalis reveals a low prevalence and limited zoonotic potential. Vector-Borne Zoonotic Dis. 2011;11:1049-55.

16. Shackleton MD, Lovari S 1997. Classification adopted for the caprine survey. In: Shackleton D (ed.) Wild sheep and goats and their relatives. Status survey and Conservation Action Plan for Caprinae. IUCN/SSC Caprinae Specialist Group, IUCN, Gland, Switzerland and Cambridge, UK. pp 3-17

17. Corlatti L, Lorenzini R, Lovari S. The conservation of the chamois Rupicapra spp. Mammal Rev. 2011;41:163-74.

18. http://www.vco2.it/index0.htm (Censimenti). Accessed 5 December 2015

19. Latini R, Asprea A. Conteggi in simultanea della popolazione di Camoscio appenninico nel PNALM: nota sintetica dei risultati autunno 2014. Ente Parco Nazionale d'Abruzzo, Lazio e Molise. 2014. http://www. camoscioappenninico.it/sites/camoscioappenninico.it/files/images/autunno_ 2014_PNALM.pdf. Accessed 5 December 2015.

20. Carnevali L, Pedrotti L, Riga F, Toso S. Banca Dati Ungulati: Status, distribuzione, consistenza, gestione e prelievo venatorio delle popolazioni di Ungulati in Italia. Rapporto 2001-2005. Biol Cons Fauna. 2009;117:1-168.

21. Lovari S, Ferretti F, Corazza M, Minder I, Troiani N, Ferrari C, et al. Unexpected consequences of reintroductions: competition between increasing red deer and threatened Apennine chamois. Anim Conserv. 2014;17:359-70.

22. Karim MR, Wang R, Yu F, Li T, Dong H, Li D, et al. Multi-locus analysis of Giardia duodenalis from nonhuman primates kept in zoos in China: geographical segregation and host-adaptation of assemblage $B$ isolates. Infect Genet Evol. 2015;30:82-8.

23. Whelan JA, Russell NB, Whelan MA. A method for the absolute quantification of CDNA using real-time PCR. J Immunol Methods. 2003;278:261-9.

24. Read C, Walters J, Robertson ID, Thompson RC. Correlation between genotype of Giardia duodenalis and diarrhoea. Int J Parasitol. 2002;32:229-31.

25. Nantavisai K, Mungthin M, Tan-ariya P, Rangsin R, Naaglor T, Leelayoova S. Evaluation of the sensitivities of DNA extraction and PCR methods for detection of Giardia duodenalis in stool specimens. J Clin Microbiol. 2007;45: 581-3.

26. Read CM, Monis PT, Thompson RC. Discrimination of all genotypes of Giardia duodenalis at the glutamate dehydrogenase locus using PCR-RFLP. Infect Genet Evol. 2004;4:125-30.

27. Santin M, Fayer R. Enterocytozoon bieneusi, Giardia, and Cryptosporidium infecting white-tailed deer. J Eukaryot Microbiol. 2015;62:34-43.

28. Wang H, Zhao G, Chen G, Jian F, Zhang S, Feng C, et al. Multilocus genotyping of Giardia duodenalis in dairy cattle in Henan, China. PLoS ONE. 2014;9(6):e100453.

29. van der Giessen JW, de Vries A, Roos M, Wielinga P, Kortbeek LM, Mank TG. Genotyping of Giardia in Dutch patients and animals: a phylogenetic analysis of human and animal isolates. Int J Parasitol. 2006;36:849-58.

30. Monis PT, Mayrhofer G, Andrews RH, Homan WL, Limper L, Ey PL. Molecular genetic analysis of Giardia intestinalis isolates at the glutamate dehydrogenase locus. Parasitology. 1996;112:1-12.

31. Souza SL, Gennari SM, Richtzenhain LJ, Pena HF, Funada MR, Cortez A, et al. Molecular identification of Giardia duodenalis isolates from humans, dogs, cats and cattle from the state of São Paulo, Brazil, by sequence analysis of fragments of glutamate dehydrogenase ( $g d h)$ coding gene. Vet Parasitol. 2007;149:258-64.

32. Prystajecky N, Tsui CK, Hsiao WW, Uyaguari-Diaz Ml, Ho J, Tang P, et al. Giardia spp. are commonly found in mixed assemblages in surface water, as revealed by molecular and whole-genome characterization. Appl Environ Microbiol. 2015;81:4827-34.

33. Lebbad M, Mattsson JG, Christensson B, Ljungström B, Backhans A Andersson JO, et al. From mouse to moose: multilocus genotyping of Giardia isolates from various animal species. Vet Parasitol. 2010;168:231-9.
34. Ruiz A, Foronda P, González JF, Guedes A, Abreu-Acosta N, Molina JM, et al. Occurrence and genotype characterization of Giardia duodenalis in goat kids from the Canary Islands, Spain. Vet Parasitol. 2008;154:137-41.

35. Robertson LJ. Giardia and Cryptosporidium infections in sheep and goats: a review of the potential for transmission to humans via environmental contamination. Epidemiol Infect. 2009;137:913-21.

36. Feng Y, Xiao L. Zoonotic potential and molecular epidemiology of Giardia species and giardiasis. Clin Microbiol Rev. 2011;24:110-40.

37. Gaffuri A, Giacometti M, Tranquillo VT, Magnino S, Cordioli P, Lanfranchi P. Serosurvey of roe deer, chamois and domestic sheep in the central Italian Alps. J Wildl Dis. 2006;42:685-90.

38. Ferretti F, Corazza M, Campana I, Pietrocini V, Brunetti C, Scornavacca D, et al. Competition between wild herbivores: reintroduced red deer and Apennine chamois. Behav Ecol. 2015;26:550-9.

39. Apollonio M, Lovari S. In: Lovari S, editor. Progetto di monitoraggio dello stato di conservazione di alcuni mammiferi particolarmente a rischio della fauna italiana. Relazione al Ministero dell'Ambiente, Servizio Conservazione della Natura - Roma. 2001. p. 481.

\section{Submit your next manuscript to BioMed Central and we will help you at every step:}

- We accept pre-submission inquiries

- Our selector tool helps you to find the most relevant journal

- We provide round the clock customer support

- Convenient online submission

- Thorough peer review

- Inclusion in PubMed and all major indexing services

- Maximum visibility for your research

Submit your manuscript at www.biomedcentral.com/submit 